\title{
Caracterização físico-química do mosto e do vinho Moscato Giallo em videiras cultivadas sob cobertura de plástico
}

\author{
Geraldo Chavarria(1), Henrique Pessoa dos Santos $^{(2)}$, Mauro Celso Zanus ${ }^{(2)}$, Cristiano Zorzan ${ }^{(2)}$ \\ e Gilmar Arduino Bettio Marodin ${ }^{(1)}$
}

\begin{abstract}
(1)Universidade Federal do Rio Grande do Sul, Departamento de Horticultura e Silvicultura, Caixa Postal 776, CEP 91540-000 Porto Alegre, RS. E-mail: geraldochavarria@hotmail.com, marodin@ufrgs.br (2)Embrapa Uva e Vinho, Caixa Postal 130, CEP 95700-000 Bento Gonçalves, RS. E-mail: henrique@cnpuv.embrapa.br, zanus@cnpuv.embrapa.br, czorzan@cnpuv.embrapa.br
\end{abstract}

\begin{abstract}
Resumo - O objetivo deste trabalho foi avaliar a influência da cobertura de plástico sobre as características físico-químicas do mosto e do vinho da cultivar Moscato Giallo. Na safra 2006, um experimento em delineamento completamente casualizado foi realizado em vinhedo com cobertura de plástico impermeável, e sem cobertura como controle. De cada vinhedo, três microvinificações $(20 \mathrm{~L})$ foram elaboradas. Foram realizadas avaliações físico-químicas quanto ao: mosto $-{ }^{\circ}$ Brix, açúcares redutores, densidade, acidez total, ácido tartárico, ácido málico e pH; e vinho - densidade, graduação alcoólica, acidez total, acidez volátil, $\mathrm{pH}$, extrato seco, açúcares redutores, cinzas, I 420, compostos voláteis e minerais. O mosto das videiras cobertas apresentou maior rendimento, porém, menor concentração de açúcares pelo fato de a maturação das uvas ter-se atrasado. Como consequiência, os vinhos do cultivo protegido tiveram menor graduação alcoólica, embora tenham sido beneficiados pela sanidade das uvas, com a redução de acetato de etila e acidez volátil. O microclima da cobertura também restringiu a concentração de alguns minerais no vinho, principalmente Pe K. A cobertura beneficiou a qualidade enológica, porém requer atraso na data de colheita, para as uvas atingirem adequada maturação fisiológica e tecnológica.
\end{abstract}

Termos para indexação: Vitis vinifera, enologia, microclima, qualidade enológica.

\section{Physicochemical characterization of must and wine Moscato Giallo from grapevines grown under plastic overhead cover}

\begin{abstract}
The objective of this work was to evaluate the plastic overhead cover (POC) effect on must and wine composition of the cultivar Moscato Giallo. In 2006 vintage, it was performed a completely randomly designed experiment, in a vineyard covered with an impermeable plastic cloth, and without covering as control. From each vineyard, three microvinification $(20 \mathrm{~L})$ were elaborated. Physico-chemical analysis were performed for: musts ${ }^{\circ}$ Brix, reducer sugar contents, density, total acidity, tartaric acid, malic acid and $\mathrm{pH}$; and wines - density, alcohol degree, acidity, volatile acidity, $\mathrm{pH}$, dry extract, reducer sugar contents, ashes, I 420, volatile compounds and minerals. The must of the covered vineyard presented higher yield, but lower sugar content, due to delay on ripening. As consequence, the POC wines showed lower alcohol degree, but with the benefit of a lower ethylacetate and volatile acidity levels. The POC microclimate also caused a decrease of some minerals (mainly P and $\mathrm{K}$ ) in the wines. POC improved the enological quality, however, this demands delay in the harvest date to achieve the adequate physiological and technological maturation of grapes.
\end{abstract}

Index terms: Vitis vinifera, enology, microclimate, wine quality.

\section{Introdução}

Vários são os fatores capazes de afetar a qualidade de um vinho. Entre eles podem ser citados: o tipo de solo, as variações climáticas, o manejo da planta e o processo de vinificação (Sanchéz \& Dokoozlian, 2005). O efeito do clima, sobretudo do microclima do vinhedo, exerce grande influência sobre a qualidade das uvas e dos vinhos, pelo fato de interferir diretamente na incidência de doenças (Agrios, 1997) e nas respostas fisiológicas das plantas (Mullins et al., 1992), que vão se refletir na síntese de compostos importantes para a qualidade enológica.

A sanidade das uvas é um aspecto importante na definição da qualidade dos vinhos (Sônego et al., 2005), o que é relevante, porque algumas doenças fúngicas 
prejudicam a produção das uvas e afetam a cor, aroma e sabor do vinho, durante o processo de vinificação e envelhecimento. Uvas com Botrytis cinerea, por exemplo, contêm maiores concentrações de tirosinase e lacase, que são enzimas responsáveis pela oxidação enzimática dos compostos fenólicos, que prejudicam a cor, o aroma e o sabor dos vinhos (Sônego et al., 2005).

A utilização da cobertura de plástico impermeável, sobre as linhas de cultivo, propicia alterações no microclima da videira, ao diminuir a água livre sobre folhas e cachos (Ferreira et al., 2004; Cardoso et al., 2008). Isto faz com que a incidência e a severidade de doenças, como podridões-de-cachos, sejam diminuídas, já que a água é o elemento ambiental primário do processo de infecção (Chavarria et al., 2007). Entretanto, embora se conheça a potencialidade da cobertura de plástico sobre a diminuição das doenças e a garantia do potencial produtivo (Chavarria et al., 2007), ainda não se dispõe de informações sobre o efeito desta tecnologia na qualidade final dos vinhos.

O objetivo deste trabalho foi avaliar o efeito da cobertura de plástico sobre o mosto e a qualidade do vinho da cultivar Moscato Giallo.

\section{Material e Métodos}

O experimento foi conduzido na safra 2006, em Flores da Cunha, RS, distrito de Mato Perso $\left(29^{\circ} 6{ }^{\prime} \mathrm{S}, 51^{\circ} 20^{\prime} \mathrm{W}\right.$ e altitude de $541 \mathrm{~m}$ ), em vinhedos de vinícola com cultivar Moscato Giallo (clone VCR1), enxertada em portaenxerto 'Kober 5BB', com espaçamento de $3 \times 0,9 \mathrm{~m}$ (3.703 plantas ha-1).

As plantas foram conduzidas em "Y", com fileiras de 35 m na direção Nordeste-Sudoeste, com poda mista, tendo-se deixado varas de seis a oito gemas e esporões de duas gemas. $\mathrm{O}$ vinhedo foi dividido em duas partes: a primeira foi constituída por 12 fileiras, cobertas na linha de cultivo com lonas de plástico trançadas de polipropileno transparentes, impermeabilizadas com polietileno de baixa densidade, com $160 \mu \mathrm{m}$ de espessura e largura de 2,65 m; na segunda, foram mantidas cinco fileiras descobertas, cujas linhas centrais foram consideradas como plantas controle.

Para a elaboração do vinho, foram colhidas, aleatoriamente, três amostras de $28 \mathrm{~kg}$ de uva, em dez plantas de cada área (coberta e descoberta). Após terem sido desengaçadas, esmagadas e prensadas, uma alíquota de $100 \mathrm{~mL}$, em cada repetição do mosto, foi retirada para realização das análises no mesmo momento.
O restante do mosto foi colocado em recipientes de vidro com capacidade de $20 \mathrm{~L}$, e a cada um deles foram adicionados $80 \mathrm{mg} \mathrm{L}^{-1} \mathrm{de} \mathrm{SO}_{2}$ e $0,03 \mathrm{~mL} \mathrm{~kg}^{-1}$ de enzima pectolítica; em seguida, foram encaminhados por decantação por 24 horas a $0^{\circ} \mathrm{C}$. Após a trasfega (sifonagem) para separação das borras, formadas durante a clarificação, foi adicionada levedura seca ativa (Saccharomyces cerevisiae - Embrapa $1 \mathrm{vvt}$ ) à proporção de $0,2 \mathrm{~g} \mathrm{~L}^{-1}$ de mosto. Não foi adicionado açúcar aos mostos. Esses recipientes $(20 \mathrm{~L})$ foram fechados com válvulas de Müller, de maneira que a fermentação do mosto se processasse em condições anaeróbias. Os recipientes foram colocados em sala com temperatura controlada de $20^{\circ} \mathrm{C}$, para a realização da fermentação. Concluída a fermentação alcoólica, constatada pela análise da concentração de açúcar residual e pelo desprendimento de dióxido de carbono, foi feita uma trasfega a fim de se separar o vinho da borra. Para a clarificação protéica, foi adicionado $1 \mathrm{~g} \mathrm{~L}^{-1}$ de bentonite (montmorilonita absorvente), previamente hidratada durante 22 horas em 20 partes de água. A estabilização tartárica do vinho foi realizada a $-3^{\circ} \mathrm{C}$, durante 21 dias. Estabilizado, o vinho foi engarrafado e conservado a $16^{\circ} \mathrm{C}$.

Os mostos e os vinhos de cada tratamento foram, então, analisados nos laboratórios de Enoquímica e de Instrumentação da Embrapa Uva e Vinho. O teor de sólidos solúveis totais ( ${ }^{\circ}$ Brix) foi obtido pela leitura em um refratômetro de bancada, com correção automática de temperatura. A densidade foi determinada por meio de densímetro digital; o álcool $\left(\% \mathrm{v} / \mathrm{v}\right.$ a $\left.20^{\circ} \mathrm{C}\right)$ foi determinado por destilação e leitura no mesmo densímetro (Miele \& Rizzon, 2006); a acidez total (meq $\left.\mathrm{L}^{-1}\right)$ foi determinada pela titulação do vinho com $\mathrm{NaOH} 0,1 \mathrm{~N}$ e azul de bromotimol como indicador; a acidez volátil (meq $\mathrm{L}^{-1}$ ) foi medida pelo arraste de vapor com titulação do vinho com $\mathrm{NaOH}$ $0,1 \mathrm{~N}$ e fenolftaleína como indicador; e o $\mathrm{pH}$ foi determinado com um potenciômetro digital, equipado com elétrodo de vidro e calibrado com solução-padrão de pH 3 e pH 4 (Miele \& Rizzon, 2006).

Os açúcares redutores e o extrato seco foram determinados conforme Rizzon \& Miele (2001); as cinzas foram obtidas pela incineração de $20 \mathrm{~mL}$ de vinho em cadinhos de platina a $530-550^{\circ} \mathrm{C}$ (Miele \& Rizzon, 2006); e o índice 420, pela medida da absorbância com espectrofotômetro a $420 \mathrm{~nm}$ (Miele \& Rizzon, 2006). 
A análise dos minerais $\mathrm{Ca}, \mathrm{Mg}, \mathrm{Fe}, \mathrm{Cu}$ e $\mathrm{Zn}$ presentes no vinho foi realizada por meio de absorção atômica, com um espectrofotômetro, enquanto o $\mathrm{K}, \mathrm{Na}$ e $\mathrm{Rb}$ foram analisados por emissão de chama, e P por colorimetria (Meneguzzo et al., 2006).

Os dados obtidos foram sumetidos à análise estatística de variância ANOVA, e as médias foram comparadas pelo teste de Tukey, a 5\% de probabilidade.

\section{Resultados e Discussão}

Foram observadas diferenças significativas em relação ao rendimento do mosto, durante o processamento (prensagem), que foi superior em 7\% nas uvas provenientes da área coberta (Tabela 1). Este maior rendimento tem, possivelmente, relação direta com a maior massa individual e conteúdo de água das bagas sob cobertura de plástico, como foi observado nesta safra (Chavarria et al., 2007).

A cobertura de plástico pode favorecer a disponibilidade hídrica das videiras, já que esta diminui a demanda evaporativa, próximo ao dossel vegetativo, em consequiência da restrição da radiação e do vento (Cardoso et al., 2008). Essas condições contribuem para a diminuição do deficit de pressão de vapor $(-57,1 \%)$, entre a camada limítrofe das folhas e a câmara subestomática, o que favorece o potencial de água e a abertura estomática (Cardoso et al., 2008). Portanto, a menor demanda evaporativa propicia melhor condição hídrica para as plantas e pode favorecer diretamente a quantidade de água nas bagas e influenciar no aumento de tamanho e massa. $\mathrm{O}$ aumento no tamanho das bagas pode ser negativo, na busca de vinhos tintos de melhor qualidade, pois bagas maiores apresentam menor relação casca/polpa, e é na casca que se localizam os compostos desejáveis (antocianinas, fenóis etc.) para o incremento enológico (Deloire et al., 2004; Conde et al., 2007).

As análises físico-químicas do mosto da 'Moscato Giallo', nos dois sistemas de produção, mostram que a cobertura de plástico impermeável propiciou menor densidade e menor quantidade de açúcares redutores (Tabela 1). Estes resultados mostram que as uvas deste tratamento não alcançaram o mesmo estádio de maturação das uvas do cultivo convencional, no momento da colheita. Isto se refletiu em menor graduação alcoólica e maior acidez total nos vinhos da área sob cobertura de plástico (Tabela 2). Este atraso na maturação da uva se deve à interferência que a cobertura exerce sobre este processo fisiológico, ao estender o período de maturação a partir da mudança de cor das bagas até a colheita, possivelmente pela diminuição da radiação solar (Rana et al., 2004). Com estas respostas, destaca-se a necessidade de atraso na data de colheita das uvas cultivadas sob cobertura de plástico, para propiciar a máxima maturação fisiológica e tecnológica. Este procedimento é possível neste sistema de cultivo, em razão da garantia fitossanitária que a cobertura de plástico propicia para o vinhedo (Chavarria et al., 2007).

A acidez condiciona a estabilidade biológica (ausência de microorganismos que prejudicam a fermentação), a cor e as características gustativas dos vinhos (Rizzon et al., 1998). A acidez do mosto e do vinho pode ser avaliada pela determinação do $\mathrm{pH}$, da acidez total e da

Tabela 1. Parâmetros físico-químicos do mosto, no período da colheita da cultivar Moscato Giallo, conduzida em "Y" sob cobertura de plástico impermeável translúcido e a céu aberto (controle). Média de três repetições ${ }^{(1)}$.

\begin{tabular}{lcccccccc}
\hline Tratamento & ${ }^{\circ}$ Brix & $\begin{array}{c}\text { Aç. redutores } \\
\left(\mathrm{g} \mathrm{L}^{-1}\right)\end{array}$ & $\begin{array}{c}\text { Densidade } \\
\left(\mathrm{g} \mathrm{mL}^{-1}\right)\end{array}$ & $\begin{array}{c}\text { Acidez total } \\
\left(\mathrm{meq} \mathrm{L}^{-1}\right)\end{array}$ & $\begin{array}{c}\text { Ác. tartárico } \\
\left(\mathrm{g} \mathrm{L}^{-1}\right)\end{array}$ & $\begin{array}{c}\text { Ác. málico } \\
\left(\mathrm{g} \mathrm{L}^{-1}\right)\end{array}$ & $\begin{array}{c}\mathrm{pH} \\
\text { Rendimento } \\
\text { em mosto }(\%)\end{array}$ \\
\hline Cobertura & $17,5 \mathrm{~b}$ & $182,0 \mathrm{~b}$ & $1,075 \mathrm{~b}$ & $74,0 \mathrm{a}$ & $5,1 \mathrm{a}$ & $2,7 \mathrm{a}$ & $3,2 \mathrm{~b}$ & $48,6 \mathrm{a}$ \\
Controle & $19,0 \mathrm{a}$ & $197,3 \mathrm{a}$ & $1,082 \mathrm{a}$ & $76,0 \mathrm{a}$ & $4,9 \mathrm{a}$ & $3,1 \mathrm{a}$ & $3,5 \mathrm{a}$ & $45,1 \mathrm{~b}$ \\
\hline
\end{tabular}

${ }^{(1)}$ Médias, nas colunas, seguidas por letras iguais, não diferem entre si, pelo teste de Tukey, a 5\% de probabilidade.

Tabela 2. Parâmetros físico-químicos do vinho da cultivar Moscato Giallo, conduzida em "Y" sob cobertura de plástico impermeável translúcido e a céu aberto (controle). Média de três repetições ${ }^{(1)}$.

\begin{tabular}{|c|c|c|c|c|c|c|c|c|c|}
\hline Tratamento & $\begin{array}{c}\text { Densidade } \\
\left(\mathrm{g} \mathrm{mL}^{-1}\right)\end{array}$ & $\begin{array}{l}\text { Álcool } \\
(\% \mathrm{v} / \mathrm{v})\end{array}$ & $\begin{array}{l}\text { Acidez total } \\
\left(\mathrm{meq} \mathrm{L}^{-1}\right)\end{array}$ & $\begin{array}{l}\text { Acidez volátil } \\
\left(\mathrm{meq} \mathrm{L}^{-1}\right)\end{array}$ & $\mathrm{pH}$ & $\begin{array}{c}\text { Extrato seco } \\
\left(\mathrm{g} \mathrm{L}^{-1}\right)\end{array}$ & $\begin{array}{c}\text { Aç. redutores } \\
\left(\mathrm{g} \mathrm{L}^{-1}\right)\end{array}$ & $\begin{array}{l}\text { Cinzas } \\
\left(\mathrm{g} \mathrm{L}^{-1}\right)\end{array}$ & $\begin{array}{l}\text { DO 420 } \\
(\mathrm{I} 420)\end{array}$ \\
\hline Cobertura & $0,992 \mathrm{a}$ & $10,20 b$ & $76,0 \mathrm{a}$ & $3,3 b$ & $3,12 b$ & $14,07 \mathrm{a}$ & $1,08 \mathrm{a}$ & $1,1 \mathrm{~b}$ & $0,059 \mathrm{~b}$ \\
\hline Controle & $0,964 \mathrm{a}$ & $11,11 \mathrm{a}$ & $54,7 \mathrm{~b}$ & $8,0 \mathrm{a}$ & $3,60 \mathrm{a}$ & $14,23 \mathrm{a}$ & $1,26 \mathrm{a}$ & $1,8 \mathrm{a}$ & $0,129 \mathrm{a}$ \\
\hline
\end{tabular}

${ }^{(1)}$ Médias, nas colunas, seguidas por letras iguais, não diferem entre si, pelo teste de Tukey, a 5\% de probabilidade. 
concentração individual dos ácidos orgânicos (Rizzon et al., 1998). Os ácidos tartárico e málico são os principais componentes responsáveis pela acidez do mosto da uva (Blouin \& Guimberteau, 2000). As concentrações destes ácidos estão relacionadas aos aspectos fisiológicos da maturação, e às características de solo, clima e práticas agronômicas (Rizzon \& Sganzerla, 2007). De acordo com os resultados obtidos, a cobertura de plástico não afetou a acidez total e a concentração dos ácidos tartárico e málico do mosto, embora o pH tenha sido menor (Tabela 1). Esta diminuição do $\mathrm{pH}$ pode ter sido afetada pela menor quantidade de cátions de potássio, como descrito por Rizzon et al. (1998).

Considerando-se o acúmulo de açúcares e a degradação dos ácidos orgânicos, pode-se inferir que as taxas de incremento de açúcar nas bagas sejam menores que as de degradação de ácidos orgânicos, pois os níveis dos ácidos no mosto tiveram comportamento diferenciado, se comparados ao cultivo convencional (Tabela 1). Pode ser que a alteração do microclima, principalmente pelo aumento das temperaturas (Lulu et al., 2005), acelere o metabolismo e a degradação do ácido málico, o que justificaria a similaridade em acidez da uva, apesar das diferenças de acúmulo de açúcares (Tabela 1). Contudo, o acúmulo de açúcares tem influência não só da temperatura, mas também da radiação solar (Mullins et al., 1992). E como a cobertura restringe em até 55\% a radiação para os cachos, pode haver um decréscimo na taxa de incremento de açúcar ao longo da maturação (Chavaria et al., 2007).

$\mathrm{O}$ atraso na maturação sob a cobertura também se refletiu na concentração de álcoois superiores do vinho, cuja soma total foi significantemente menor em relação ao cultivo convencional (Tabela 3 ). Isto, possivelmente, resulta da menor quantidade de açúcares nas uvas cobertas, pois são parâmetros químicos diretamente relacionados (Jackson, 2000).

$\mathrm{O}$ pH é uma das características mais importantes do vinho, pois além de interferir na cor, exerce um efeito pronunciado sobre o gosto. Vinhos com pH elevado são mais suscetíveis às alterações oxidativas e biológicas, uma vez que o teor de dióxido de enxofre ativo é proporcionalmente menor (Aerny, 1985). O pH do vinho do tratamento coberto foi significativamente inferior, conforme havia sido observado no mosto (Tabelas 1 e 2). A maior acidez total e $\mathrm{pH}$ dos vinhos do tratamento coberto pode ser atribuída ao menor conteúdo de potássio dos mostos (Tabela 4), pois quanto menor a quantidade desse mineral, menor é a precipitação do ácido tartárico na forma de bitartarato de potássio, durante a vinificação (Rizzon et al., 1998).

A quantidade de minerais no vinho pode ser influenciada por fatores como a fertilidade do solo, as práticas de fertilização, o estado hídrico da planta e as condições de vinificação (Maarse et al., 1987). De acordo com os resultados obtidos, no vinho do cultivo protegido foram observadas quantidades significativamente menores de $\mathrm{Mg}, \mathrm{Na}, \mathrm{Mn}, \mathrm{Rb}$ e,

Tabela 3. Compostos voláteis dos vinhos da cultivar Moscato Giallo, conduzida em "Y" sob cobertura de plástico impermeável translúcido e a céu aberto (controle). Média de três repetições ${ }^{(1)}$.

\begin{tabular}{|c|c|c|c|c|c|c|c|c|}
\hline Tratamento & $\begin{array}{l}\text { Aldeído } \\
\text { acético }\end{array}$ & $\begin{array}{l}\text { Acetato } \\
\text { de etila }\end{array}$ & Metanol & 1-Propanol & $\begin{array}{l}\text { 2-Metil- } \\
\text { 1-propanol }\end{array}$ & $\begin{array}{l}\text { 2-Metil- } \\
\text { 1-butanol }\end{array}$ & $\begin{array}{l}\text { 3-Metil- } \\
\text { 1-butanol }\end{array}$ & $\begin{array}{c}\text { Álcoois } \\
\text { superiores }\end{array}$ \\
\hline Cobertura & $51,3 a$ & $23,5 b$ & $25,8 \mathrm{a}$ & $8,1 \mathrm{a}$ & $12,1 \mathrm{a}$ & $22,6 a$ & $120,4 a$ & $163,2 b$ \\
\hline Controle & $44,4 \mathrm{a}$ & $38,2 \mathrm{a}$ & $30,8 \mathrm{a}$ & $11,6 \mathrm{a}$ & $19,5 \mathrm{a}$ & $25,1 \mathrm{a}$ & $128,4 a$ & $184,5 \mathrm{a}$ \\
\hline
\end{tabular}

(1)Médias, nas colunas, seguidas por letras iguais, não diferem entre si, pelo teste de Tukey, a 5\% de probabilidade.

Tabela 4. Minerais dos vinhos da cultivar Moscato Giallo, conduzida em "Y” sob cobertura de plástico impermeável translúcido e a céu aberto (controle). Média de três repetições ${ }^{(1)}$.

\begin{tabular}{|c|c|c|c|c|c|c|c|c|c|c|c|}
\hline Tratamento & $\mathrm{P}$ & $\mathrm{K}$ & $\mathrm{Ca}$ & $\mathrm{Mg}$ & $\begin{array}{c}\mathrm{Na} \\
-(\mathrm{mg} \\
\end{array}$ & $\mathrm{Fe}$ & $\mathrm{Cu}$ & $\mathrm{Zn}$ & $\mathrm{Mn}$ & $\mathrm{Rb}$ & $\begin{array}{c}\mathrm{Li} \\
\left(\mu \mathrm{g} \mathrm{L}^{-1}\right)\end{array}$ \\
\hline Cobertura & $35,3 b$ & $495,9 b$ & $38,9 a$ & $44,7 b$ & $14,4 b$ & $0,4 a$ & $0,1 \mathrm{a}$ & $0,1 \mathrm{a}$ & $1,0 \mathrm{~b}$ & $2,7 b$ & $4,8 \mathrm{a}$ \\
\hline Controle & $82,5 a$ & $820,0 \mathrm{a}$ & $39,2 \mathrm{a}$ & $51,9 \mathrm{a}$ & $15,1 \mathrm{a}$ & $0,4 \mathrm{a}$ & $0,2 \mathrm{a}$ & $0,3 \mathrm{a}$ & $1,2 \mathrm{a}$ & $3,5 \mathrm{a}$ & $3,9 a$ \\
\hline
\end{tabular}

${ }^{(1)}$ Médias, nas colunas, seguidas por letras iguais, não diferem entre si, pelo teste de Tukey, a 5\% de probabilidade. 
principalmente P e K (Tabela 4). Estes menores teores de minerais são também confirmados pela menor concentração de cinzas no vinho (Tabela 2).

O fósforo teve concentrações $57 \%$ menores nos vinhos da área com cultivo protegido (Tabela 4). Levando-se em consideração que este nutriente aumenta ao longo da maturação (Manfroi et al., 2006), os resultados se mostram coerentes, já que nas diversas avaliações foi caracterizado um atraso da maturação em função da cobertura de plástico.

A concentração média de potássio foi $43 \%$ menor no cultivo protegido (Tabela 4). De acordo com a literatura, a variação na concentração deste nutriente está intimamente ligada à cultivar, às condições climáticas na época de desenvolvimento das bagas, temperaturas na fermentação, pH, duração de armazenamento, percentual de álcool e equilíbrio iônico do vinho (Manfroi et al., 2006). Em algumas regiões vitícolas, como na região de Santana do Livramento, no Rio Grande do Sul, o excesso de potássio associado à baixa concentração de ácido tartárico pode ser indesejável, por influenciar no aumento do $\mathrm{pH}$ do vinho (Rizzon et al., 1998).

De maneira geral, esta menor quantidade na concentração de minerais, nos vinhos do cultivo protegido, pode estar relacionada às mudanças que a cobertura de plástico exerce no microclima (Mota et al., 2008) e à conseqüente diferenciação na absorção de água pelas videiras. Como já foi abordado anteriormente, as coberturas diminuem a demanda evaporativa e o deficit de pressão de vapor (Cardoso et al., 2008). Deste modo, as videiras cobertas perdem menos água para a atmosfera e absorvem menos água do solo. Como decorrência deste menor fluxo transpiratório, as plantas podem realizar menor absorção e acúmulo de minerais (Masle et al., 1992).

Apesar de o microclima sob a cobertura restringir o consumo de água e favorecer melhor aporte hídrico para a planta, o fato de a cobertura condicionar a água superficial $(0-30 \mathrm{~cm})$ apenas na região de entrelinha (Cardoso et al., 2008) é outro ponto a ser considerado nas diferenças nas concentrações de minerais na baga. Em conseqüência disto, as coberturas condicionam a redistribuição do sistema radical da região da linha para a entrelinha. Como este experimento foi realizado aos dois anos após o início da cobertura, o sistema radical talvez não estivesse completamente alocado na entrelinha, o que pode ter influenciado a absorção de minerais.
Os valores de acidez volátil dos vinhos das áreas coberta e descoberta foram de 3,3 e $8 \mathrm{meq} \mathrm{L}^{-1}$, respectivamente (Tabela 2). Os menores valores de acidez volátil, alcançados no vinho da área coberta, estão associados à maior sanidade das uvas, que apresentaram menor incidência e severidade de podridões-de-cacho, sobretudo de podridão-ácida, que é a principal causadora deste defeito no vinho (Chavarria et al., 2007). Isto também foi comprovado pela significativa redução de acetato de etila (-38\%), no vinho da área coberta, em relação à descoberta (Tabela 3 ). Além disso, o índice 420 foi menor nos vinhos sob cobertura de plástico, o que indica que estes apresentaram menor intensidade de cor amarela (Tabela 2). Isto demonstra que esses vinhos apresentaram menor quantidade de oxidações, possivelmente em consequiência da sanidade das uvas. Assim, vinhos brancos e jovens, produzidos com uvas com maiores quantidades de podridões-de-cacho, poderão apresentar índice 420 mais elevado (Jackson, 2000). No entanto, estádios de maturação mais avançados também podem estar associados a colorações mais intensas (Meneguzzo et al., 2006). No presente estudo, as uvas do cultivo convencional estavam mais maduras comparadas às cobertas. A diminuição do índice 420 ressalta a sanidade das uvas provenientes da cobertura de plástico, já que esta substância se trata de um marcador desta característica (Meneguzzo et al., 2006).

Esta melhoria fitossanitária, propiciada pela cobertura, é importante para as uvas brancas, como a 'Moscato Giallo', que apresentam maior suceptibilidade à podridões-de-cachos (Sônego et al., 2003). Assim, a melhoria da sanidade das uvas destaca-se como uma das grandes contribuições, que o cultivo protegido das videiras pode propiciar, e apresenta-se como alternativa na busca do incremento da qualidade dos vinhos, em regiões que apresentam excesso de chuvas no período da maturação.

\section{Conclusões}

1. As uvas 'Moscato Giallo' da área coberta apresentam maior rendimento de mosto, porém, pelo fato de atrasarem a maturação nessa condição, apresentam menor concentração de açúcares.

2. Os vinhos do cultivo protegido, como conseqüência do atraso na maturação, apresentam menor graduação alcoólica; porém, são beneficiados com a sanidade das uvas, o que reduz os níveis de acetato de etila e acidez volátil. 
3. Os vinhos do cultivo protegido apresentam diminuição no conteúdo de alguns minerais, principalmente fósforo e potássio.

4. O fato de as uvas 'Moscato Giallo' no sistema de produção protegida atrasarem a maturação requer atraso na data de colheita, para que possam atingir o mesmo teor de açúcar do mosto e a graduação alcoólica do vinho obtido em sistema convencional.

\section{Referências}

AERNY, J. Définition de la qualité de la vendange. Revue Suisse de Viticulture, Arboriculture, Horticulture, v.17, p.219-223, 1985.

AGRIOS, G.N. Plant Pathology. $4^{\text {th }}$ ed. London: Academic Press, 1997. 633p.

BLOUIN, J.; GUIMBERTEAU, G. Maturation et maturité des raisins. Bordeaux: Éditions Féret, 2000. 151p.

CARDOSO, L.S.; BERGAMASCHI, H.; COMIRAM, F.; CHAVARRIA, G.; MARODIN, G.A.B.; DALMAGO, G.A.; SANTOS, H.P.; MANDELLI, F. Alterações micrometeorológicas em vinhedos pelo uso de coberturas de plástico. Pesquisa Agropecuária Brasileira, v.43, p.441-447, 2008.

CHAVARRIA, G.; SANTOS, H.P.; SÔNEGO, O.R.; MARODIN, G.A.B.; BERGAMASCHI, H.; CARDOSO, L.S. Incidência de doenças e necessidade de controle em cultivo protegido de videira. Revista Brasileira de Fruticultura, v.29, p.477-482, 2007.

CONDE, C.; SILVA, P.; FONTES, N.; DIAS, A.C.P.; TAVARES, R.M.; SOUSA, M.J.; AGASSE, A.; DELROT, S.; GERÓS, H. Biochemical changes throughout grape berry development and fruit and wine quality. Food, v.1, p.1-22, 2007.

DELOIRE, A.; OJEDA, H.; CARBONNEAU, A.; WANG, Z. Determinación y control del estado hídrico de la vid: efectos morfológicos y fisiológicos de la restricción hídrica en vides. Viticultura Enología Profesional, v.90, p.27-43, 2004.

FERREIRA, M.A.; PEDRO JÚNIOR, M.J.; SANTOS, A.O.; HERNANDES, J.L. Modificação parcial do ambiente de cultivo da videira 'Cabernet Sauvignon' sobre diferentes porta-enxertos: efeito sobre a produção e o teor de sólidos solúveis. Bragantia, v.63, p.439-445, 2004.

JACKSON, R.S. Wine science: principles, practices, perception. $2^{\text {nd }}$ ed. San Diego: Academic Press, 2000. 654p.

LULU, J.; CASTRO, J.V.; PEDRO JÚNIOR, M.J. Efeito do microclima na qualidade da uva de mesa 'Romana' (A 1105) cultivada sob cobertura plástica. Revista Brasileira de Fruticultura, v.27, p.422-425, 2005.

MAARSE, H.; SLUMP, A.C.; TAS, A.C.; SCHAEFER, J. Classification of wines according to type and region based on their composition. Zeitschrift für Lebensmittel Untersuchung undForschung A, v.184, p.198-203, 1987.

MANFROI, L.; MIELE, A.; RIZZON, L.A.; BARRADAS, C.I.N. Composição físico-química do vinho Cabernet Franc proveniente de videiras conduzidas no sistema lira aberta. Ciência e Tecnologia de Alimentos, v.26, p.290-296, 2006.

MASLE, J.; FARQUHAR, G.D.; WONG, S.C. Transpiration ratio and plant mineral content are related among genotypes of a range of species. Australian Journal of Plant Physiology, v.19, p.709721, 1992.

MENEGUZZO, J.; RIZZON, L.A.; MIELE, A.; AYUB, M.A.Z. Efeito de Botrytis cinerea na composição do vinho Gewürztramine. Ciência e Tecnologia de Alimentos, v.26, p.527-532, 2006.

MIELE, A.; RIZZON, L.A. Efeito de elevadas produtividades do vinhedo nas características físico-químicas e sensoriais do vinho Merlot. Ciência Rural, v.36, p.271-278, 2006.

MOTA, C.S.; AMARANTE, C.V.T.; SANTOS, H.P.; ZANARDI, O.Z. Comportamento vegetativo e produtivo de videiras 'Cabernet Sauvignon' cultivadas sob cobertura plástica. Revista Brasileira de Fruticultura, v.30, p.148-153, 2008.

MULLINS M.G.; BOUQUET, A.; WILLIAMS, L.E. Biology of the grapevine. Cambridge: Cambridge University, 1992. 239p.

RANA, G.; KATERJI, N.; INTRONA, M.; HAMMAMI, A. Microclimate and plant water relationship of the "overhead" table grape vineyard managed with three covering techniques. Scientia Horticulturae, v.102, p.105-120, 2004.

RIZZON, L.A.; MIELE, A. Avaliação da cv. Cabernet Franc para elaboração de vinho tinto. Ciência e Tecnologia de Alimentos, v.21, p.249-255, 2001.

RIZZON, L.A.; SGANZERLA, V.M.A. Ácidos tartárico e málico no mosto de uva em Bento Gonçalves, RS. Ciência Rural, v.37, p.911-914, 2007.

RIZZON, L.A.; ZANUS, M.C.; MIELE, A. Evolução da acidez durante a vinificação de uvas tintas de três regiões vitícolas de Rio Grande do Sul. Ciência e Tecnologia de Alimentos, v.18, p.179-183, 1998.

SÁNCHEZ, L.A.; DOKOOZLIAN, N.K. Bud microclimate and fruitfulness in Vitis vinifera L. American Journal of Enology and Viticulture, v.56, p.319-329, 2005.

SÔNEGO, O.R.; GARRIDO, L. da R.; GRIGOLETTI JÚNIOR, A. Doenças fúngicas. In: FAJARDO, T.V.M. (Ed.). Uva para processamento: fitossanidade. Brasília: Embrapa Informação Tecnológica, 2003. p.11-44. (Série Frutas do Brasil, 35).

SÔNEGO, O.R.; GARRIDO, L. da R.; GRIGOLETTI JÚNIOR, A. Principais doenças fúngicas da videira no Sul do Brasil. Bento Gonçalves: Embrapa Uva e Vinho, 2005. 25p. (Embrapa Uva e Vinho. Circular técnica, 56).

Recebido em 7 de janeiro de 2008 e aprovado em 23 de junho de 2008 